Fuster Morell, M. Governance of online creation communities for the building of digital commons: Viewed through the framework of the institutional analysis and development. Madison, M. J., Strandburg, K., \& Frischmann, B. Frischmann, B., Strandburg, K. \& M. Madison (eds.). Governing the Knowledge Commons. Oxford University Press.

\title{
Governance of online creation communities for the building of digital commons: Viewed through the framework of the institutional analysis and development
}

Mayo Fuster Morell, PhD

Fellow. Berkman center for Internet and society

www.onlinecreation.info

\begin{abstract}
This chapter addresses the governance of a specific type of constructed commonpool resource, online creation communities (OCCs). OCCs are communities of individuals that mainly interact via a platform of online participation, with the goal of building and sharing a common-pool resource resulting from collaboratively systematizing and integrating dispersed information and knowledge resources. Previous research of the governance of OCCs has been based on analyzing specific aspects of the governance. However, there has been a gap in the literature, one of lacking a comprehensive and holistic view of what governance means in collective action online. This chapter provides a set of dimensions that define the governance of OCCs. Particularly, most previous work did not consider infrastructure provision in their analysis. This chapter challenges previous literature by questioning the neutrality of infrastructure for collective action. The governance of OCCs is here analyzed through the institutional analysis and development (IAD) framework, building on Madison, Frischmann, and Strandburg's (2010) adaptation of this framework to constructing commons in the cultural environment. References to Schweik and English's adaptation of IAD to free and open source communities will also be made. The empirical data are drawn from a statistical analysis of 50 cases and four case studies on OCCs (Wikipedia, Flickr, Wikihow, and Openesf). The empirical analysis results in a set of models of OCCs governance. The conclusions provide an assessment of the utility of IAD in the analysis of OCCs, and Madison, Frischmann, and Strandburg's adaptation. Additionally, it ends by addressing the defining characteristics of digital commons.
\end{abstract}


Fuster Morell, M. Governance of online creation communities for the building of digital commons: Viewed through the framework of the institutional analysis and development. Madison, M. J., Strandburg, K., \& Frischmann, B. Frischmann, B., Strandburg, K. \& M. Madison (eds.). Governing the Knowledge Commons. Oxford University Press.

\section{Introduction}

Natural commons have been studied substantially using the Institutional Analysis and Development (IAD) framework of Ostrom (1990) and many others. More recently, a new type of commons has also attracted the attention of researchers. (Hess and Ostrom 2005) Constructing commons in the cultural environment as characterized by Madison, Frischmann, and Strandburg (2010) refers to a broader set of commons in the field of culture and knowledge. This chapter addresses a specific type of constructed cultural common-pool resource: online creation communities.

With the adoption of information and communication technologies (ICTs), diverse types of communities of individuals following common goals through technologically mediated communication have emerged. (Benkler 2006) Online creation communities (OCCs) are a particular type of online community whose goal is knowledge-making and sharing. OCCs are communities of individuals that mainly interact via a platform for online participation, with the goal of building and sharing a common-pool resource (or common pool of resources) resulting from collaboratively systematizing and integrating dispersed information and knowledge resources and cognitive capacities.

Previous work on the governance of OCCs

One of the more lively debates in contemporary organizational research concerns how the coordination and governance of distributed knowledge in globally dispersed settings - such as the case of OCCs - takes place, and how it can be accounted for. (Becker 2001; Hansen 1999; Orlikowski 2002) Unlike other types of online communities, OCCs must integrate individual contributions into a common pool, which can heighten interdependencies and the 
Fuster Morell, M. Governance of online creation communities for the building of digital commons: Viewed through the framework of the institutional analysis and development. Madison, M. J., Strandburg, K., \& Frischmann, B. Frischmann, B., Strandburg, K. \& M. Madison (eds.). Governing the Knowledge Commons. Oxford University Press.

need for coordination and governance. Yet little is known about how OCCs which organize around production govern themselves.

The scant empirical research on OCCs governance is mainly concentrated on the case of Free and Open Software Projects (FLOSS), (Crowston and Howison 2005; Lanzara and Morner 2004; O’Mahony 2007; O’Mahony and Ferraro 2007; Weber 2004) and more recently on Wikipedia. (Burke and Kraut 2008; Ciffolilli 2003; Kittur, Suh, Pendleton, and Chi 2007; Kriplean, Beschastnikh, McDonald, and Golder 2007; Loubser and Pentzold 2009; O'Neil 2009; Reagle 2007; Stadler and Hirsh 2002; Tkacz 2007; Viégas, Wattenberg, and Mckeon 2007) These analyses focus on the community, (Konieczny, 2009; Greenstein and Devereau 2009; Tkacz 2007) particularly in terms of policy-making in the community, (Kriplean, Beschastnikh, McDonald, and Golder 2007; Loubser, and Pentzold 2009; Viégas, Wattenberg, and Mckeon 2007) its decentralized character, (Forte and Bruckman 2008; Malone 2004) and forms of conflict resolution. (Kittur, Suh, Pendleton, and Chi 2007; Matei and Caius 2011) The nature of authority has also been analyzed, (Ciffolilli 2003; O'Neil 2009; Stadler and Hirsh 2002) together with studies on modes of selection of administrators, their roles, (Burke and Kraut 2008) and leadership. (Reagle 2007) Fuster Morell (2010) considered the institutional frame or, more specifically, the role of the Wikimedia Foundation as platform provider.

Although the number of articles on community governance has increased, their range of topics remains limited. Previous research has mostly focused on analyzing the policy-making processes developed by the participants to govern their interaction. However, there was a gap in the literature, lacking a comprehensive and holistic view of what governance means in collective action online.

This chapter aims to move beyond the analysis of specific aspects of the governance of OCCs, to provide a comprehensive understanding of the diverse aspects that drive governance of OCCs. This chapter provides a set of dimensions that define the governance of OCCs. In particular, most previous work did not consider infrastructure provision in their analysis. In 
Fuster Morell, M. Governance of online creation communities for the building of digital commons: Viewed through the framework of the institutional analysis and development. Madison, M. J., Strandburg, K., \& Frischmann, B. Frischmann, B., Strandburg, K. \& M. Madison (eds.). Governing the Knowledge Commons. Oxford University Press.

this regard, the chapter challenges previous literature by questioning the neutrality of infrastructure for collective action.

Empirical analysis: Institutional Analysis and Development (IAD) framework

The governance of OCCs will be analyzed though the Institutional Analysis and Development (IAD) framework, building on the work of Madison, Frischmann and Strandburg who adapt IAD from natural commons to constructed commons in the cultural environment. References to Schweik and English's (2012) adaptation of IAD to FLOSS will also be made. In this regard, the chapter will also provide an assessment of IAD in the analysis of OCCs.

The empirical data were drawn from a statistical analysis of 50 cases and four case study comparisons on OCCs conducted in 2010. (Fuster and Morell 2010)

For the statistical analysis of 50 units, a codebook was used to collect the data from digital threads available at the OCCs websites. In the case of OCCs, random selection is difficult given that the universe is unknown. Nevertheless, the sample tried to reflect the heterogeneity of OCCs. For the sampling, a snowball method was used. The strategy employed in selecting the units for the sample was based on selecting the cases which fulfilled the OCCs definition and had a global scope. From the cases that conformed to these two criteria, the cases covered were a variety of OCCs following two central sampling guidelines. First, there had to be a balance between more recent and older organizations. Secondly, there had to be a balance between the several types of technological base and knowledge goal central interests of the OCCs (e.g., multi-media archives, libraries, encyclopedias, dictionaries, information nodes, software programs, collective social memory, among others).

The statistical analysis pointed to four models of governance that will be presented though the chapter. These informed the selection of the four case studies, each associated with one of the four models. The four case studies were Wikipedia, Wikihow, Flickr, and the Social 
Fuster Morell, M. Governance of online creation communities for the building of digital commons: Viewed through the framework of the institutional analysis and development. Madison, M. J., Strandburg, K., \& Frischmann, B. Frischmann, B., Strandburg, K. \& M. Madison (eds.). Governing the Knowledge Commons. Oxford University Press.

Forums Memory project. Wikipedia is an encyclopedia made up of free content that emerged from 2001. Editors collaborate to create encyclopedic articles. Its infrastructure is provided by the Wikimedia Foundation. Wikihow is a collaborative "how to" manual. The Wikihow provider is a start up with the same name founded in 2005. Flickr is a platform provided by Yahoo! for sharing and archiving visual materials. Participants interact to improve and comment on each other's pictures, collaborate to create "albums" of photos around a particular topic, or create learning groups around photography techniques. Openesf.net is a platform provided by the European Social Forum, a collectivity of social movements in Europe. Openesf.net was set up to support collectible document forums. The case studies were based on virtual ethnography, interviews and participative observations at events. Data was collected in 2008 and 2010 . $^{\mathrm{i}}$

\section{Online creation communities viewed through an analytical framework directed at institutional analysis and development}

This section views OCCs through the analytical framework of institutional analysis and development (IAD). Reference is made to the adaptation of Madison, Frischmann and Strandburg (2010) of the framework to constructed commons (see figure I). First, resource characteristics, community attributes, and the governance of OCCs are presented. In the following section, OCCs outcomes are presented along with an analysis of how resource characteristics, community attributes, and rules-in-use/governance might impact upon them.

Figure I: Institutional Analysis and Development (IAD)

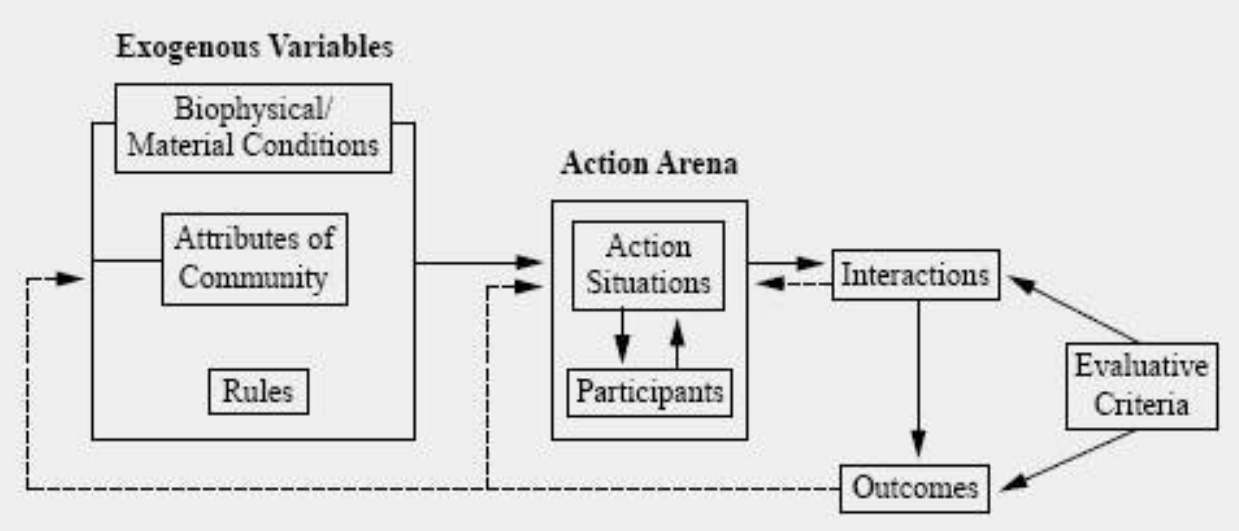


Fuster Morell, M. Governance of online creation communities for the building of digital commons: Viewed through the framework of the institutional analysis and development. Madison, M. J., Strandburg, K., \& Frischmann, B. Frischmann, B., Strandburg, K. \& M. Madison (eds.). Governing the Knowledge Commons. Oxford University Press.

Madison, Frischmann and Strandburg provide a characterization of the cultural environment as being that within which commons construction emerges. They also recognize that the background environment for a particular commons may need further specification and analysis in order to situate the description, classification and analysis of resource characteristics, community attributes, and governance institutions. In the analysis of OCCs, a specific environmental setting is involved and needs to be considered. The Internet is the

specific environment within which OCCs emerge and their common-pool resource is hosted. The Internet as an environment is shaped by the digital culture, the technological constraints of virtual spheres, as well as the legal frameworks that regulate it.

\section{A. Resource characteristics of OCCs}

The pooled resources in OCCs are not given resources that need to be "preserved" as in natural commons-pool resources. Rather, they are resources that need to be built. OCCs, indeed, arise from the collective goal of building a specific resource. The building process is characterized by the pooling of dispersed information and cognitive capacities in evolving bodies of shared knowledge. The resource tends to be conceived of as a permanent work in progress, and in most of the cases, without a specific moment of definitive conclusion.

The OCCs are immaterial in nature, consisting of information and knowledge. As public goods, they are non-rivalrous and non-excludable. Madison, Frischmann, and Strandburg (2010) classify constructed commons goals as existing in a milieu of Intellectual Property (IP) 
Fuster Morell, M. Governance of online creation communities for the building of digital commons: Viewed through the framework of the institutional analysis and development. Madison, M. J., Strandburg, K., \& Frischmann, B. Frischmann, B., Strandburg, K. \& M. Madison (eds.). Governing the Knowledge Commons. Oxford University Press.

rights, that is existing only because of the IP rights, or mediating among communities with different default norms. Most OCCs, including the four case studies considered here, fall into the first category, as they exist as part of IP rights.

According to Madison, Frischmann, and Strandburg (2010) cultural commons are diverse in terms of the level at which their pooled resources are most easily identifiable or recognized. OCCs form a case where pooled resources are easily identifiable - an archive that gathers and coherently systematizes the contributions. Indeed, the construction of an integrated and identifiable piece of knowledge is what distinguishes OCCs from other online communities such as networking sites or communities of support or shared interest. An encyclopedia is the main common resource in the case of Wikipedia, a picture repository in the case of Flickr, how to manuals in the case of Wikihow, and organizational information linked to a forum in the case of Openesf. However, beyond their principal resources, all the cases agglutinate other secondary "pooled resources" which deepen one another. For example, Wikipedia is not only an encyclopedia, but also hosts a repository of audio-visual sources as a commons. Additionally, even if the knowledge resource is the central goal around which OCCs interact, OCCs also depend on an infrastructure to support interaction, and so an infrastructure architecture also results from the process. However, this is considered in deep, "infrastructure,", meaning something that sustains the main goal, but is not itself the central goal of the process.

Schweik and English (2012) have previously attempted to apply IAD to OCCs in the specific case of FLOSS. Regarding resources characteristics, our approaches differ in two ways to Schweik and English. On the one hand, Schweik and English do not specify the type of resource. However, when analyzing diverse OCCs as is the case in this chapter, specifying the type of resource is appropriate. On the other hand, Schweik and English present as resources characteristics aspects, such as the participation platform design, that are integrated as part of governance, not as resources characteristics, in the present work. 
Fuster Morell, M. Governance of online creation communities for the building of digital commons: Viewed through the framework of the institutional analysis and development. Madison, M. J., Strandburg, K., \& Frischmann, B. Frischmann, B., Strandburg, K. \& M. Madison (eds.). Governing the Knowledge Commons. Oxford University Press.

\section{B. Community attributes of OCCs}

It was pointed out above that pooled resources in OCCs are easily identifiable but that the same cannot be said of their communities. In terms of communities of constituents, OCCs are complex. OCCs are open to participation, and it is difficult to identify their boundaries. For none of the four case studies or in the sample of fifty cases of OCCs looked at herein, were clear boundaries or membership established. The communities of OCCs may include any person potentially willing to contribute to the common-pool resource or to use it.

\section{Community size}

OCCs are generally open to participation, but such openness does not necessarily result in actual participation. The size of the community of participants depends substantially on the goal of each OCC, ranging from more broad to more restricted sets of interests. One rightly expects that an encyclopedia attracts more participants than a site organized around visualization techniques.

In terms of the participation in the four case studies, Wikipedia achieves a high level of participation. Almost 18 million registered users were part of Wikipedia in November 2012. Flickr also draws a large amount of participation. In 2007, one estimate put the Flickr community at 7.7 million users. (Negoescu and Gatica-Perez 2008) Wikihow has substantially fewer participants. As of April 2010, the number of registered Wikihow participants was around 213,204. The levels of participation at openesf.net are low, with less than 1200 people registered at their highest point. ${ }^{\text {ii }}$

\section{Voluntary engagement}


Fuster Morell, M. Governance of online creation communities for the building of digital commons: Viewed through the framework of the institutional analysis and development. Madison, M. J., Strandburg, K., \& Frischmann, B. Frischmann, B., Strandburg, K. \& M. Madison (eds.). Governing the Knowledge Commons. Oxford University Press.

Participants in OCCs are volunteers. They do not have a contractual labor relationship with the community, even if some participants may make their contributions as part of their work outside the community. All four cases share this characteristic of voluntary participation. Notably, however, professional photographers who use Flickr as part of their work form a significant part of the Flickr population. (Burgess 2007)

As a consequence of the voluntary character of OCCs, each participant assumes the costs of participation. The participants are able to contribute according to their own resources of time, skills or money. According to the civic voluntarism model, (Verba, Schlozman, and Brady 1995) resources are a key factor in understanding why some people participate whereas others do not. Resource-rich participants with free time, connectivity, skills and money can contribute more easily than those without such resources. And so the resource-rich tend to be disproportionately represented among participants. However, a lack of resources may not be the only explanatory variable behind non-participation. Even people with the necessary resources may decide not to participate for a variety of reasons such as questions of identity or personality. People who identify themselves as creative, for example, and/or are more used to public exposure may be more likely to participate. This is the case for younger generations. According to Preece, Nonnecke and Andrews (2004), other reasons why people do not participate in OCCs are as follows: thinking that they were being helpful by not posting; wanting to learn more about the community before diving in; not being able to use the software because of poor usability; not liking the dynamics that they observed within the group; or feeling represented in what was said by other participants.

\section{Community heterogeneity}

Several authors have pointed out that OCCs are very diverse in terms of the motivations 
Fuster Morell, M. Governance of online creation communities for the building of digital commons: Viewed through the framework of the institutional analysis and development. Madison, M. J., Strandburg, K., \& Frischmann, B. Frischmann, B., Strandburg, K. \& M. Madison (eds.). Governing the Knowledge Commons. Oxford University Press.

and interest that drive their participation. (e.g., Benkler 2006; Weber 2004) However, Schweik and English (2012) point out that their surveys of participants in FLOSS show a high level of homogeneity in terms of social composition, in concrete, in terms of gender (predominantly male), age (predominantly young) and geographical origin (predominantly Europe and USA). Our own analysis of gender distribution at openesf.net also shows that the predominance of male participation was also repeated in the case of openesf.net, where $36 \%$ of active participants are women according to their name or/and presentation in their user page. In the

case of Wikipedia, previous research has concluded that women accounted for around $12 \%$ of the editor community. (Glott, Schmidt, and Ghosh 2009) According to Wikihow Inc, the Wikihow community has a higher women's participation rate of around 40\%. (Interview, Wikihow founder, 2008)

\section{External relationships}

Madison, Frischmann, and Strandburg (2010) suggest, with respect to community attributes, analyzing external relationships of community and common-pool resources regarding markets, industries or firms. For the specific case of FLOSS, several studies have pointed out how corporations and foundations engage with the common-pool resource, which Schweik and English $(2012,15)$ refer to with the label "open-source ecosystem". The external relationships of OCCs may explain their capacity to mobilize participation. However, research in this area is very limited, and there is not a unique pattern of interaction with markets, industries or firms. In the cases presented here we can observe the development of "net districts" similar to an industrial district. OCCs that are part of a "net district" and cooperate with each other. This is the case of Wikipedia and Wikihow that adopt the same license or protocols to facilitate the flow of content and participation between their platforms. 
Fuster Morell, M. Governance of online creation communities for the building of digital commons: Viewed through the framework of the institutional analysis and development. Madison, M. J., Strandburg, K., \& Frischmann, B. Frischmann, B., Strandburg, K. \& M. Madison (eds.). Governing the Knowledge Commons. Oxford University Press.

\section{Rules-in-use or governance of OCCs}

Ostrom (2005: 3) defines institutions (referred to herein as bodies with governance or rules-in-use) as "the prescriptions that humans use to organize all forms of repetitive and structured interactions." Institutions raise and channel interaction among participants. They provide direction, control and coordination of the collective action. Institutions are set by social norms and formalized rules, together with the forms in which those rules are created and enforced. (Ostrom 2005)

The governance, or the direction, control and coordination of a process, is embedded or operates though aspects or points/sources of power. According to the analysis reported here, there are eight main aspects that are in a complex juxtaposition or interaction which determine and drive governance in OCCs. The eight dimensions (that operate at the different operational, collective choice and constitutional levels) that give OCCs direction, control and coordination are:

i) Collective mission or goal of the process.

ii) Cultural principles/Social norms.

iii) Design of the platform of participation (where regulation is embedded in the code).

iv) Self-management of contributions: autonomous condition of participants in allocating their contribution to the building process.

v) Formal rules or policies applied to community interaction.

vi) License.

vii)Decision-making and conflict resolution systems with regard to community interaction.

viii) Infrastructure provision. .ii $^{\text {i }}$

The eight dimensions are interrelated rather than narrowly discrete. Additionally, governance is not "static", but dynamic and might evolve over time. It might not be linear in its 
Fuster Morell, M. Governance of online creation communities for the building of digital commons: Viewed through the framework of the institutional analysis and development. Madison, M. J., Strandburg, K., \& Frischmann, B. Frischmann, B., Strandburg, K. \& M. Madison (eds.). Governing the Knowledge Commons. Oxford University Press.

evolution, with "incoherent" moves in the diverse aspects on occasion.

Governance is very much shaped on the basis of how and who decides and manages these dimensions. Each of the dimensions might be managed in a more open to participation or inclusive way or not. They may encourage involvement or consideration of the views and interests of the participants as individuals and/or community as a whole. Or they may be contrasted by the infrastructure provider. Another important dimension is whether it is more decentralized / fragmented / ad hoc or more centralized and established.

Some of these aspects are similarly present in other forms of collective action, while others are specific to the OCCs. This might be connected to the background environment within which OCCs operate, particularly the functioning of the digital environment. OCCs take place in an environment that shapes them in terms of technical and legal constraints. The emerging governance of OCCs in this environment cannot be qualified as simple. Indeed it is a highly complex system.

In the following section each of these eight aspects will be presented in detail.

\section{i) Collective mission or goal of the process}

In general, the goal or mission of OCCs is building and sharing a common-pool resource. The specific mission is defined by the early participants or by the infrastructure provider. Then, the overall system is shaped by experiences with fulfillment of this initial mission. However, participants do not need to identify with the mission or the project as a whole in order to contribute.

It is common in OCCs to define their goals in terms of a sentence that describes their mission. Wikipedia's mission reads, "Imagine a world in which every single human being can freely share in the sum of all knowledge". Wikihow's mission is "to build the world's largest, highest quality, free how-to manual in many languages". Openesf.net does not have its own 
Fuster Morell, M. Governance of online creation communities for the building of digital commons: Viewed through the framework of the institutional analysis and development. Madison, M. J., Strandburg, K., \& Frischmann, B. Frischmann, B., Strandburg, K. \& M. Madison (eds.). Governing the Knowledge Commons. Oxford University Press.

mission, but is a "tool" for supporting the working groups in their roles within a much larger process, the ESF, whose goal or motto is that "another world is possible". Flickr's mission is "Share your photos. Watch the world."

Generally, the mission is defined by the founder of the OCCs. In OCCs culture, the founders tend to be considered relevant and visible figures, especially with Wikipedia where there is just one. The role of the founder might change over time, from more central and with formal power, to less central or only symbolic, such as the case of Jimmy Wales for Wikipedia, or the founders of Flickr. In the case of Wikihow, the figure of the founder maintained its position over time, as owner of Wikihow Inc. In contrast, Openesf did not generate such a figure, but the founders of the process are connected, keeping their position. Giving importance to the figure of the founder is connected to a social norm (meritocracy) and is presented in the following section which considers importance given to values merited.

\section{ii) Cultural principles/social norms}

There is a set of cultural principles and values that tend to be present transversally in the culture of OCCs. These also feed the way these eight dimensions are performed and function. Among these key principles are: openness and "freedom to operate", meritocracy, and flexibility. Openness and "freedom to operate" without seeking permission or preclearance by a manager or property owner (in Benkler's terms, 2006, 2013), might be present though the license that favors freedom to access and use the resource, or freedom though the openness of the process and the autonomy of the participants to allocate his or her own participation. Meritocracy or "doacracy" refers to valuing individuals on the base of the quantity and quality of their contributions, not on the basis of "who" they are in terms of external credentials or their opinions. Doacracy also refers to the tendency in some OCCs for whoever does something to also have authority over it. Flexibility refers to the methods or pre-established formats. OCCs tend to be more mission oriented - accomplish something - than method oriented - to do something in a particular manner. Benkler (2013) refers to this question by pointing to the "indeterminity" of the governance of peer production.

In the following section, further social norms will be presented, as they are also present 
Fuster Morell, M. Governance of online creation communities for the building of digital commons: Viewed through the framework of the institutional analysis and development. Madison, M. J., Strandburg, K., \& Frischmann, B. Frischmann, B., Strandburg, K. \& M. Madison (eds.). Governing the Knowledge Commons. Oxford University Press.

in the way the platform is designed.

\section{iii) Design of the platform of participation (where regulation is embedded in the code)}

In OCCs, it is relatively rare for individuals to be involved in direct dialogues and negotiations amongst themselves. Instead, individuals interact with the platform design. Platform design thus influences participation and interaction. In this section, the design of the

platform of participation and social norms is presented. As we will see from the analysis, the way in which the environment is designed by the code of the platforms is very much in line with the OCC's social norms.

The design of the participation platform is embedded and regulated in the code. Many diverse code programs can support a platform of participation. Here we present a set of principles embedded in the platforms that embody and guide participation in OCCs. The provision of the platform is controlled by the infrastructure provider. More or less involvement from the community in the platform design depends on the level of openness of the infrastructure providing community involvement.

\section{Openness}

\subsection{Openness as it applies to the access to the resource}

Openness as applied to the access to the resource is defined by Madison, Frischmann and Strandburg $(2010,695)$ as "our capacity to relate to a resource by accessing and using it".

In terms of the conditions of access and use of the resources in OCCs, as we will see later, free licenses favor free use. Yet how the knowledge resources are actually made available also determines the possibility of accessing and using them. In this regard, it is common for the 
Fuster Morell, M. Governance of online creation communities for the building of digital commons: Viewed through the framework of the institutional analysis and development. Madison, M. J., Strandburg, K., \& Frischmann, B. Frischmann, B., Strandburg, K. \& M. Madison (eds.). Governing the Knowledge Commons. Oxford University Press.

common-pool resource in OCCs to be hosted by a participation platform made accessible in an open access condition. The open access condition of the resources should not however lead us to think they are not regulated, as they are.

These knowledge resources are open access through their license and through being made openly available online. The open access condition of the resources does not imply openness when understood as the degree of control and intervention in decision making of those conditions. Deciding the license terms and how the resource is made available online are in the hands of the infrastructure provider. The level of openness to decision making about the conditions of use of the resources (as stated in the license and embedded in the platform of participation), here again, depends on the level of openness of the infrastructure provider.

\subsection{Openness as it applies to the community building the resource}

Openness to interrelation and participation within the community for collaborative common-pool resource building is a significant principle at work in OCCs. Openness to participation is made operative through the provision of channels that allow intervention in content creation, as well as through the protocols that guide those channels. Protocols refer, for example, to low requirements for credentials to participate.

According to the statistical analysis conducted for 50 cases, (Fuster Morell 2010) OCCs usually have an average of four different channels of participation (i.e., the possibility to add comments to a specific section of the content, upload materials, and edit Web pages, among others). The protocols that guide participation in OCCs appear to incentivize participation in a high percentage of the cases (i.e., $80 \%$ of the registration systems allow automatic registration without requiring any filter to become part of the platform). This contributes to lowering the transaction costs involved in becoming an active contributor. In all of the four case studies discussed here, indicators for the importance of openness are present: they all employ easy to use technology and channels for open participation, and they do not ask for credentials or 
Fuster Morell, M. Governance of online creation communities for the building of digital commons: Viewed through the framework of the institutional analysis and development. Madison, M. J., Strandburg, K., \& Frischmann, B. Frischmann, B., Strandburg, K. \& M. Madison (eds.). Governing the Knowledge Commons. Oxford University Press.

other requirements in order to intervene.

However, even if openness to participation is embedded in the technology of OCCs, not all OCCs are equally accessible. The level of inclusion of OCCs and the willingness or capacity to ensure there are no barriers to participation vary. For example, an analysis of OCC inclusion shows OCCs to be exclusive in terms of accessibility for people with relevant physical disabilities. (Fuster Morell 2010)

The principle of openness to participation is not only embedded in the design of the platform of participation, it is also present in social norms. For instance, in OCC discourses, it is emphasized that the community is provided accessibility for participation. In this line, Wikipedia is presented as "the encyclopedia that anyone can edit". iv

\section{Modularity and decentralized participation}

Another aspect embedded in the code of the platform of participation is the modular organization of the platform. Essentially, this involves splitting content into separate units (such as articles, software packages, thematic albums of pictures, etc.). The design of OCCs does not imply that all participants are involved in all projects or modules. Instead, and particularly as the OCC grows, there is a tendency for participation to split or fragment into projects or modules. Modularity favors the decentralization of activity. In addition, distributing tasks between modules favors increased participation. The participation of many people in a single (central) place could be more difficult to handle than that of many small groups. Modular design and the resulting decentralization of participation are features present in the Wikipedia, Wikihow and openesf.net cases.

Concerning the Wikipedia case, activities which involve the entire Wikipedia community are extremely rare. Most of the activities of Wikipedia are based on interactions of small groups. The same finding was uncovered in the Wikihow case. In openesf.net, $41.5 \%$ of the 
Fuster Morell, M. Governance of online creation communities for the building of digital commons: Viewed through the framework of the institutional analysis and development. Madison, M. J., Strandburg, K., \& Frischmann, B. Frischmann, B., Strandburg, K. \& M. Madison (eds.). Governing the Knowledge Commons. Oxford University Press.

projects are composed by only one member, and projects with 3 members are the most frequent following this (20.8\%). The Flickr case is different because its primary unit of content is not based on collective "projects" such as an article in Wikipedia, but on individual acts (uploading photos). In this regard, rather than decentralization as such, we find structural individualization at the base of the design of the participation platform. However, in Flickr too, we find the feature of the formation of separate groups around common interests. According to Sieberg, there were 300,000 groups on Flickr by 2007. (Sieberg 2007)

\section{Participation is mostly asynchronous and online}

As presented in the previous section, participation is decentralized to projects in OCCs. Furthermore, it is not implied in terms of either the platform design or social norms that participants congregate at the same time within the platform. Asynchronous participation in the platform is common to all the case studies.

One moment at which some participants might congregate at the same time and place is during physical encounters. Even if OCCs are mainly developed online, participants do sometimes meet physically. In the Wikipedia and openesf.net cases, regular local meetings of participants are organized. Plus, both of these case study OCCs hold an annual meeting. Wikihow and Flickr participants meet much more infrequently.

\section{Transparency of participation}

OCCs are developed in public, indeed it would be accurate to say that OCCs live in public. The analysis of 50 cases of OCCs showed that in $88 \%$ of the cases the content of communications among participants is publicly accessible. That is, it is possible to read the content of communications among participants without registering on the site. 
Fuster Morell, M. Governance of online creation communities for the building of digital commons: Viewed through the framework of the institutional analysis and development. Madison, M. J., Strandburg, K., \& Frischmann, B. Frischmann, B., Strandburg, K. \& M. Madison (eds.). Governing the Knowledge Commons. Oxford University Press.

The public, or transparent, character of the organizational process favors openness to participation. Public organizing also favors the training of new participants, and the building of trust. New participants can see how others perform some tasks. Finally, it also favors the autonomy and decentralization of participation and the coordination of participation without a predefined plan or a gatekeeper distributing roles. Participants themselves can identify where contributions are needed and to what level they wish to get involved. According to O'Mahony's (2007: 148) research on FLOSS communities "a public or transparent development process is necessary to support decentralized decision-making so that a large body of people can learn enough to participate in decisions." (O'Mahony 2007: 148)

In the Wikipedia case the whole drafting process, not only the resulting content, is visible to all. The channels that host the interaction (such as Wikis, mailing lists, meet-ups, etc.) are public by default. The same is true of Wikihow. In the case of openesf.net, each project creator may choose how public each project will be. They decide whether the project will be accessible to the general public, only to people registered at openesf.net, or only to members of that particular project. However, the majority of the projects have a public character. The same may be said concerning Flickr, albeit at an individual level. On Flickr, each individual chooses if their content is publicly accessible or not and, thereby, if the communication surrounding the content is public or not.

\section{iv) Self-management of contributions: The autonomous condition of participants in contributing to the building process}

As pointed out in the previous section, the design of the platform of participation determines, to a large degree, the type of interaction and actions that can be performed by participants. Still, the participants have great flexibility in terms of the types of activities they develop and degrees of involvement they undertake. Participants decide their level of 
Fuster Morell, M. Governance of online creation communities for the building of digital commons: Viewed through the framework of the institutional analysis and development. Madison, M. J., Strandburg, K., \& Frischmann, B. Frischmann, B., Strandburg, K. \& M. Madison (eds.). Governing the Knowledge Commons. Oxford University Press.

commitment and how they want to contribute freely and automatically on the basis of personal interests, motivations, resources and abilities. The distribution of participation is not based on centralized planning of user activities, but on decentralized, volunteers deciding for themselves. There is no gatekeeper or similar role in charge of prodding participants along in a particular direction. In the designed platform participants choose what to do. Participation is not driven by command, but by self-direction. Additionally, participants "build" or "do". Participation is mainly based on implementing tasks by directly creating or editing content. This is not a major risk. Online interaction facilitates the undoing of actions, and so mistakes are not irreparable. This implies that there is no separation between decision-making and implementation, or between a delegation and an implementation body. Those who take care of a task also have the authority to decide about how to perform it. This form of participation opens up the idea of doography or "implementation democracy". Finally, the coordination of participation is not the result of a strict, absolute and fixed plan. Rather it is open to uncertainty and variation, based on principles of randomness and the serendipitous.

This is so for the four case studies. That said, the Flickr platform is the most restrictive in terms of the types of activities that can be performed. Additionally, for some of the activities on Flickr, in contrast to the other cases, participants must pay for access, which may restrict access to some of the population.

\section{High flexibility on the typology and degree of involvement}

Not all participants necessarily carry out the same tasks. They choose among several, such as adding new content, editing content, and classifying content, among others. One person may contribute unedited information while another participant takes care of editing it and increasing its quality. Some tasks may require more effort and commitment than others, however, and in most cases, tasks are highly divided so that each participant can contribute 
Fuster Morell, M. Governance of online creation communities for the building of digital commons: Viewed through the framework of the institutional analysis and development. Madison, M. J., Strandburg, K., \& Frischmann, B. Frischmann, B., Strandburg, K. \& M. Madison (eds.). Governing the Knowledge Commons. Oxford University Press.

either just a small part of a module or a large part, facilitating the scaling of participation. Again, this must not be confused with a lack of structure. On the contrary the platforms are highly structured. There are also different levels of commitment to the platform in terms of time and active task performance. Participants' freedom to decide their level of contribution results in a very common distribution feature in OCCs. Research on the distribution of participation suggests a very unequal distribution known as the 90/9/1 principle or a power law. (Hill, Hollan, Wroblewski, and McCandless 1992; Nielsen 1997) 90\% of visitors to OCCs tend to be lurkers who read or observe but never contribute, 9\% contribute a little from time to time, and $1 \%$ contribute often and account for almost all the content and system activity. (Nielsen, 2006) In other words, there are three main profiles of participation: strong or very active, weak, and non-participant, each playing a role. Very active participants have a high degree of commitment to the process and dedicate a great deal of time and a large volume of work or complex effort to it. Low level participants are people who contribute only sporadically. Weak participation may favor greater connectivity of the OCC with other processes. Weak ties favor reaching larger areas of information. (Granovetter 1983) Beyond strong and weak participation, non-participation or unintended participation is also present and plays a role.

Non-participation could be characterized as free riding behavior. However, free riding, and in general the fact that a large percentage of people do not contribute, does not necessarily constitute a problem or put at risk the achievement of the common goals of OCCs. ${ }^{\mathrm{v}}$ With exhaustible goods, such as natural resources which can be "used up" and are costly to extract, free riding constitutes a problem. But in a context where ICTs have substantially decreased the cost of reproduction of information and information-based goods, like those provided by OCCs, OCCs do not necessarily face scarcity problems linked to the resource use. When goods are non-exhaustible, non-competitive and exclusion from their use is costly, then free riding is not necessarily a problem. It has even been said that OCCs are anti-rival. (Weber, 
Fuster Morell, M. Governance of online creation communities for the building of digital commons: Viewed through the framework of the institutional analysis and development. Madison, M. J., Strandburg, K., \& Frischmann, B. Frischmann, B., Strandburg, K. \& M. Madison (eds.). Governing the Knowledge Commons. Oxford University Press.

2004) They are not only non-rival in the sense that they can tolerate free riding without reducing their stock of value, but are actually anti-rival in the sense that OCCs positively benefit from free riders. That is, ironically, the comedy of the commons, the value of the outcome of OCCs increases when more people use them. (Frischmann 2012; Rose 1994) This implies that for any participant, contributor or "free rider", mere "use" implies a contribution. Nevertheless, this is only so where there is a sufficient number of contributors that assure the building of the resource.

The value of the information resources resulting from OCCs increases through several mechanisms as more people "use" them. First, non-participants contribute due to positive network effects. A network effect is that effect that one participant in an OCC has on the value of that OCC for other people, even if this was not intentional. When network effects appear more people become involved in an OCC, and the more valuable it becomes. For example, as more people use Flickr as a tool to connect with others, the more valuable it becomes since users can potentially connect with a larger number of people through it.

Second, in online environments most actions are translated into digital information, known as digital threads, and the elaboration of these digital threads form a source of very valuable information for the improvement of content and the functioning of the environment. They can provide, for example, relational and attention data. The environment can learn about the connections between content according to how users navigate, or the number of times an article was visited or downloaded could be used as an indicator of the quality of that article.

Third, non-participants also play a role as an audience. Free rider audiences increase the relevance and value of a platform's content and increase the motives for participation.

Finally, it is also worth considering that even though exclusion is present in OCCs, restricting access to non-participants can be costly. Technically this might be challenging. Additionally, digital culture values "simple", "easy-to-use" solutions. To incorporate filters might constitute an additional step that reduces the simplicity of the system and restricts its 
Fuster Morell, M. Governance of online creation communities for the building of digital commons: Viewed through the framework of the institutional analysis and development. Madison, M. J., Strandburg, K., \& Frischmann, B. Frischmann, B., Strandburg, K. \& M. Madison (eds.). Governing the Knowledge Commons. Oxford University Press.

openness.

The distinction between strong/weak/non-participants is also present in the four case studies.

Previous analyses of Wikipedia have addressed the question of participation distribution and showed that contributions to Wikipedia also present strong inequalities. Ortega and Gonzalez-Barahona (2007) and Ortega (2009) conclude that less than $10 \%$ of the total number of authors are responsible for more than $90 \%$ of the total number of contributions or, conversely, $90 \%$ of active editors are responsible for less than $10 \%$ of the total number of contributions. The evolution of this inequality has remained very stable over time (with a typical value of between $80 \%$ and $85 \%$ of content produced by a "core team"). However, the authors also point out that the "core team" of very active participants is not necessarily formed by the same individuals over time.

Concerning the Wikihow case, from the analysis of a random day, it emerged that the top ten participants were responsible for almost half of the content produced that day (46.5\%). ${ }^{\text {vi }}$ Wikihow interviewees reported a similarly unequal distribution of participation as that found in Wikipedia. (B. Megas, Interview, August 28, 2009; N. Willson, Interview, August 28, 2009) In the words of Wikihow's founder: "Wikihow follows power law. . . You have to support the very minimal contribution or the very small contributions of people who wouldn't actually interact with it - while it's not obvious that they create value for the whole, they really do. So you need to allow the whole thing, so the ecosystem flourishes and can be successful." (J. Herrick, Interview, December 4, 2008)

Shirky reports that the top ten participants among the total 118 contributors contributed half of the content on an event uploaded on Flickr. (2008: 123) The analysis of openesf.net showed that $18 \%$ of the participants generated content and $82 \%$ of the participants did not. Within the $18 \%$ of content generators, $3.7 \%$ were very active participants and $14.3 \%$ were less active participants. 
Fuster Morell, M. Governance of online creation communities for the building of digital commons: Viewed through the framework of the institutional analysis and development. Madison, M. J., Strandburg, K., \& Frischmann, B. Frischmann, B., Strandburg, K. \& M. Madison (eds.). Governing the Knowledge Commons. Oxford University Press.

This unequal distribution of participation does not seem to be interpreted as a problem in OCCs. On the contrary, equal participation and contributions are not expected. GerardM, an active wikipedian, spoke out in a mailing list against the idea of regular equal contributors and for valuing all community forms: "When you divide people up in groups, when you single out the "most valuable" ones (because they contribute more), you in effect divide the community. . . . When you label groups of people, you divide them and it is exactly the egalitarian aspect (independently of their contribution) that makes the community thrive." (GerardM e-mail to the mailing list Wiki-research-1, October 21, 2008) Additionally, from an outcomes perspective, the Wikipedia community accomplishes its goal. Wikipedia is the largest encyclopedia in history. Sue Gardner, executive director of the Foundation, puts it in these terms: "We need sufficient people to do the work that needs to be done. (...) But the purpose of the project is not participation." (Angwin and Fowler 2009) There does not seem to be a problem with a lack of participation in Wikipedia. On the contrary, in some instances problems linked to "too much participation" occur. This happens when levels of participation are so high that technically the system is not able to sustain the amount of activity and collapses. This occurred after the 11 September 2001 attacks and Obama's election, when many people wanted to keep Wikipedia updated. (T. Finc, Interview, November 20, 2009)

\section{v) Formal rules or policies applied to community interaction}

OCCs, particularly as they evolve from more initial stages, tend to establish formal rules. Formal rules may be restricted and limited to rules defined by the legal framework in which the OCCs operates (terms of use and license), or they may be more or less expansive including a set of principles or complex bureaucratic policies. However, O'Mahony (2003) points out that developers in FLOSS resist formal methods. The existence of too many established rules and procedures is generally perceived as problematic in OCCs. Benkler 
Fuster Morell, M. Governance of online creation communities for the building of digital commons: Viewed through the framework of the institutional analysis and development. Madison, M. J., Strandburg, K., \& Frischmann, B. Frischmann, B., Strandburg, K. \& M. Madison (eds.). Governing the Knowledge Commons. Oxford University Press.

(2013) points to a relative feature in the non-definitive character of governance mechanism in peer production: even with formal rules, there is also the social norm that a rule can be broken if that makes sense for fulfilling a task.

Lanzara and Morner (2003) pointed out that it is not that traditional mechanisms of governance and coordination are non-existent or irrelevant in OCCs. In this sense, the governance of FLOSS projects results in a combination of formal organizational mechanisms and decentralized and spontaneous mechanisms for the community platform. (Lanzara and Morner 2003) According to these authors, the presence of formal organizational features, however, does not really play a dominant or pervasive role in FLOSS projects, and taken alone would not be strong enough to account for the impressive performance of large size projects.

In terms of the possibility to control and intervene in the definition of rules, on some occasions rules (and when applied roles) are defined by the communities. According to the analysis of 50 cases, in $51 \%$ of cases it is the community that is considered to be in charge of deciding policies and the distribution of tasks and roles. In the rest of the cases, rules are defined by the infrastructure provider.

In the cases of Wikipedia, openesf.net and Wikihow, the approach is that the community is in charge of defining policies, and also of choosing the people to fulfill roles where these are created, such as site administrators.

In the case of Wikipedia, the community collaborates in wiki pages to define common policies and administrators are chosen through elections. However, there is a general feeling among the participants that there are too many policies and that their overwhelming number results in the exclusion of new participants. (Lih 2009)

Wikihow follows the same approach as Wikipedia, although the Wikihow case sees more intervention from the provider. For example, administrators are not selected by the community but by the provider.

In the case of openesf.net, there is no distinction between providers and community and 
Fuster Morell, M. Governance of online creation communities for the building of digital commons: Viewed through the framework of the institutional analysis and development. Madison, M. J., Strandburg, K., \& Frischmann, B. Frischmann, B., Strandburg, K. \& M. Madison (eds.). Governing the Knowledge Commons. Oxford University Press.

so all infrastructure governance is based on community self-governance. However, these were defined during physical meetings of the web team charged with maintaining openesf.net, not by the openesf.net platform participants as the platform did not generate enough participation to develop a community dynamic of interaction.

In the case of Flickr, although each individual can choose conditions of access and other aspects that will apply to the content they generate, participants cannot decide the policies and rules of overall interaction. Furthermore, no roles or responsibilities for the maintenance of the platform are assigned to participants. Importantly, there is no collective decision-making over the roles and rules of the platform, these are defined by Yahoo!. In this regard, Flickr participation does not imply participation in governance in terms of defining the rules that govern community interaction.

\section{vi) License (of the common-pool resource and code)}

The license is a foundational rule in OCCs in the sense that it defines the resource management regime for the common-pool resource, the resources contributed and shared. The license also mediates the relationships between the constructed commons regime and the intellectual property regimes, where relevant. There are various types of licenses (from copyright, to several options of creative commons licenses that are more flexible on users' rights, and others). The license applies to both the common-pool resource (and the contributions of the participants) and the software code of the platform of participation.

Most OCCs in this study adopted free licenses for their content (68.1\% of cases). (Fuster Morell 2010) This favors the free use of the common-pool resource by all and the freedom to use the resources under less restrictive conditions. Additionally, where the software is also free (78\% of the cases), this means that the platform of participation may be replicated somewhere else independently of the infrastructure provider. In this case, content can be moved, and it is 
Fuster Morell, M. Governance of online creation communities for the building of digital commons: Viewed through the framework of the institutional analysis and development. Madison, M. J., Strandburg, K., \& Frischmann, B. Frischmann, B., Strandburg, K. \& M. Madison (eds.). Governing the Knowledge Commons. Oxford University Press.

possible to re-launch interaction in a different context. This is known as forking. Forkability empowers the community with respect to the infrastructure provider as the community can leave and start interacting somewhere else. (Weber 2004) However, not all OCCs have the conditions that allow this.

Wikipedia, Wikihow and openesf.net are all based on FLOSS and collective free licenses, and are therefore forkable. Flickr is based on individually defined licenses and proprietary software - its content is only free insofar as individual participants choose free licenses for their content.

\section{vii) Decision-making and conflict resolution systems in community interaction}

Governance of OCCs depends on decision making institutions, including conflict resolution. Consensus decision-making is common in OCCs, yet they are also characterized by the pluralism of methods or polymorphism that involves the coexistence of several working or decision-making styles. This implies that there is no single way to solve all the situations of the platform, but a flexible approach that adopts several methods. The methodological pluralism of OCCs may appear to signal a lack of coherence in the overall system. However, for some researchers, this apparently chaotic diversity becomes a powerful resource for knowledge making and innovation. (Brown and Duguid 1991) The plurality of methods is also linked to the fact that OCCs tend to select methods according to their effectiveness in fulfilling their mission. The famous FLOSS catchphrase, "rough consensus and running code" captures the sense that actions which contribute to the accomplishment of the mission are more valuable than the precise use of a method.

In terms of polymorphy or plural methods, in Wikipedia most activity is primarily based on open groups on specific articles using consensus decision-making. However, the community combines this with a heterogeneous, sometimes secondary, mechanism to force decision- 
Fuster Morell, M. Governance of online creation communities for the building of digital commons: Viewed through the framework of the institutional analysis and development. Madison, M. J., Strandburg, K., \& Frischmann, B. Frischmann, B., Strandburg, K. \& M. Madison (eds.). Governing the Knowledge Commons. Oxford University Press.

making, block the violation of policies and contain the process within certain margins. On some occasions alternative forms of decision-making such as polls and voting are adopted. There are also administrators with particular powers, tasks assigned historically to respected individuals and a charismatic leader (the founder).

In terms of plural methods Wikihow follows a similar approach to Wikipedia. Openesf uses mainly consensus decision making. Flickr is different to the other cases because the norms and in general the overall governance system are not defined by the community of participants, but by Yahoo! as Flickr's provider.

\section{viii) Infrastructure provision (technically, legally and economically sustains the platform of participation)}

Infrastructure provision solves some of the other questions OCCs raise, and very much define the process and shape OCCs governance. Frischmann (2012) has also approached infrastructure in terms of its management as a commons. Infrastructure providers technically, legally and economically sustain the platform of participation where the community interacts. It involves the management of the servers and domain name, and covering the costs these involve, among others. O'Mahony (2007) and Lanzara and Morner (2003) have researched provision in the case of FLOSS. However, previous analyses of OCCs have dedicated little attention to this issue and infrastructure governance is considered a "backstage" question in OCCs.

Infrastructure provision can function and be governed in diverse ways. Two main axes concerning infrastructure provision strategies can be distinguished: open versus closed to community involvement in infrastructure provision, and freedom and autonomy versus dependency on infrastructure (see figure II). 
Fuster Morell, M. Governance of online creation communities for the building of digital commons: Viewed through the framework of the institutional analysis and development. Madison, M. J., Strandburg, K., \& Frischmann, B. Frischmann, B., Strandburg, K. \& M. Madison (eds.). Governing the Knowledge Commons. Oxford University Press.

Figure II. Models across the two axes of infrastructure governance

Freedom \& Autonomy

Netenabler

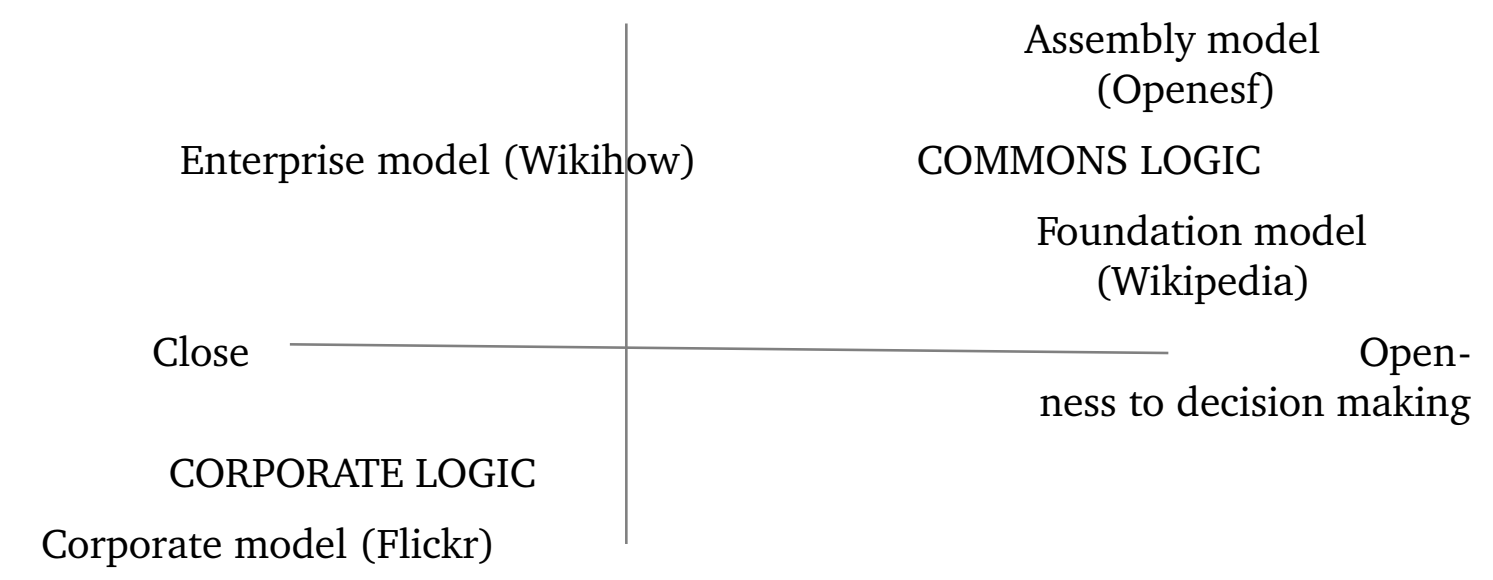

Black box

Dependency

Legend: $\mathrm{Y}=$ Freedom and autonomy of community from the provider; $\mathrm{X}=$ Involvement of the community in the provider body.

Participation in the provider space dimension (axes $\mathrm{X}$ in figure II) is closed when there is no possibility of involvement. Participation in the provider space is considered partly open where this depends on fulfilling certain criteria related to participation in the platform (such as a number of contributions). It is considered open when participation in the provider space is possible for anyone, that is, participation is regulated through self-selection.

Freedom and autonomy versus dependency on the infrastructure (net-enabler versus black box) dimension (axes $\mathrm{Y}$ in figure II) is linked to the license held for the common-pool resources and to the type of software used for the platform of participation. Net-enabler conditions are defined by a copyleft license and the use of FLOSS code, while black box conditions are defined by copyright and proprietary software. There is a qualitative difference 
Fuster Morell, M. Governance of online creation communities for the building of digital commons: Viewed through the framework of the institutional analysis and development. Madison, M. J., Strandburg, K., \& Frischmann, B. Frischmann, B., Strandburg, K. \& M. Madison (eds.). Governing the Knowledge Commons. Oxford University Press.

between relational settings in which the OCCs is "locked" into the platform, and those where the community interaction is free and autonomous with respect to the platform. If the platform cannot be reproduced, the community relationship is "closed" within the specific platform which is dependent on the provider. If the platform can be replicated (can be forkable), the relationships are free from the specific platform provider. FLOSS and copyleft licensing allow platforms to be replicated, while proprietary software and restrictive or less open copyright license regimes do not. In other words, the use of FLOSS and a copyleft license creates conditions in which the community can have greater autonomy and freedom from the platform provider.

An analysis of how 50 cases perform on the two specified axes of infrastructure governance was developed. (Fuster Morell 2010) From the analysis resulted four clusters of cases. These four provision models can be defined: corporation service (which is the case of Flickr), mission enterprise (Wikihow), autonomous representational foundation (Wikipedia) and assemblarian self-provision models (openesf.net) (see figure II).

The corporation model applies to cases of infrastructure platforms owned by companies with large pools of technological skills such as Yahoo!, the provider of Flickr. The corporate model of infrastructure governance is characterized by a provider body closed to participant involvement and based on black box conditions. It follows a for-profit strategy. Participants are "trapped" in the platform (unless they exit), as the copyright and proprietary software framework restricts the freedom and autonomy of the participants in the platform.

The mission enterprise model is characterized by being for-profit, and hence closed to participant involvement. Importantly, the enterprise model is based on net-enabler conditions, which favor the autonomy of collaboration. Furthermore, according to the statistical analysis, the enterprise model is characterized by more net-enabler conditions than the foundation model. The enterprise model applies to startups which maintain independence from big communications companies. It is a strategy for developing new business models which are 
Fuster Morell, M. Governance of online creation communities for the building of digital commons: Viewed through the framework of the institutional analysis and development. Madison, M. J., Strandburg, K., \& Frischmann, B. Frischmann, B., Strandburg, K. \& M. Madison (eds.). Governing the Knowledge Commons. Oxford University Press.

compatible with net-enabler conditions. This is the case of Wikihow.

The autonomous representational foundation model is characterized by a provider body which is (relatively) open to participant involvement as it uses some formal filters. This model is also characterized by promoting the freedom and autonomy of collaboration (net-enabler). Additionally, they are non-profit. Being relatively open to participant involvement implies that they are formal and involve some requirement to take part, not based only on the self-selection of participants. In this regard it can be considered a hybrid form (partly open, partly closed). OCCs following this model are less open than the assembly model, which is based on total openness of the provision body. They are also less net-enabler than the assembly and enterprise models. The foundation model comprises the case of Wikipedia. O'Mahony (2007) researched the governance of FLOSS communities via case studies based on the autonomous representation foundation model (2007). She characterized the foundation model as community management. However, she left the questions of the characteristics of governance models other than community management and the degree to which community management can be applied to types of providers other than open foundations.

The self-provision assembly model is characterized by being the most open in terms of provision. A self-selected community of participants can be part of the provision body in this model. It follows an informal organizing logic (without a board or legal entity) and is nonprofit oriented. Additionally, the assembly model assures the most net-enabler conditions. The assembly model applies to openesf.net.

\section{Models of OCCs governance}

In the previous sections, the eight dimensions that give direction and govern OCCs were presented. In this section, we present how these eight dimensions link one another.

The analysis of the juxtaposition or interaction between the eight dimensions reveals 
Fuster Morell, M. Governance of online creation communities for the building of digital commons: Viewed through the framework of the institutional analysis and development. Madison, M. J., Strandburg, K., \& Frischmann, B. Frischmann, B., Strandburg, K. \& M. Madison (eds.). Governing the Knowledge Commons. Oxford University Press.

that infrastructure provision is central. Infrastructure provision also determines some of the other eight aspects linked to the governance of OCCs. Infrastructure provision involves the provision of the platform of participation and the control over its design (code), the license, formal policies (such as terms of use), and, on some occasions, initiates the process and establishes the mission, and controls decision-making on conflicts around community interaction (see figure III). Still some other dimensions, like self-management of contributors in self-directing their action is not controlled by the infrastructure provider. There is any command mechanism that force contributors or direct their actions.

Figure III. Dimensions of OCCs governance that might be controlled by the infrastructure provider (in italic)

i) Collective mission or goal of the process.

ii) Cultural principles/Social norms.

iii) Design of the platform of participation (where regulation is embedded in the code).

iv) Self-management of contributions: autonomous condition of participants in allocating her or his contribution to the building process.

v) Formal rules or policies applied to community interaction.

vi) License.

vii) Decision-making and conflict resolution system with regard to community interaction.

viii) Infrastructure provision.

Legend: In italics the dimensions that might be controlled by infrastructure provider.

In this regard, the modality of governance of the infrastructure also contributes to shaping other dimensions of governance (see figure IV). Where there is openness to 
Fuster Morell, M. Governance of online creation communities for the building of digital commons: Viewed through the framework of the institutional analysis and development. Madison, M. J., Strandburg, K., \& Frischmann, B. Frischmann, B., Strandburg, K. \& M. Madison (eds.). Governing the Knowledge Commons. Oxford University Press.

community involvement in infrastructure provision (representative foundation case of Wikipedia and self-assemblarian models of openesf), the community has, structurally, more control over the design of the platform of participation and the license.

Furthermore, according to the statistical analysis of 50 cases, openness to community involvement in infrastructure provision is correlated with a community having a decisionmaking mechanism, (Fuster Morell 2010: 155) a role in conflict resolution at the community level, deciding its formal rules, a free license that also grants that the community owns the common-pool resource, and net-enabler conditions (including the right to fork). However, some of these aspects (a community having a decision-making mechanism and a role in conflict resolution at the community level, deciding its formal rules, having a free license) are also present in the mission enterprise model of Wikihow even if this model is closed to community involvement in infrastructure provision.

The corporate model of Flickr is where most sources of control are in the hands of the infrastructure provider, and the community of users (both individually and collectively) is most disempowered in comparison to the other cases. In the corporate model of Flickr, the community does not have control over the design of the platform of participation, does not have decision mechanisms and does not defines the rules, and the license does not favor community autonomy, but dependency on the infrastructure provider (see figure IV).

Figure IV. The eight dimensions of OCC infrastructure in each of the models

\begin{tabular}{|l|l|l|l|l|}
\hline & \multicolumn{1}{|c|}{ Corporation } & \multicolumn{1}{|c|}{$\begin{array}{c}\text { Mission } \\
\text { enterprise }\end{array}$} & $\begin{array}{l}\text { Representationa } \\
\mathbf{1} \text { foundation }\end{array}$ & $\begin{array}{c}\text { Self-provision } \\
\text { assembly }\end{array}$ \\
\hline Mission & $\begin{array}{l}\text { Defined by the } \\
\text { provider }\end{array}$ & $\begin{array}{l}\text { Either defined by } \\
\text { community or } \\
\text { provider }\end{array}$ & $\begin{array}{l}\text { Either defined by } \\
\text { community or } \\
\text { provider }\end{array}$ & Community \\
\hline Social norms & Community & Community & Community & Community \\
\hline $\begin{array}{l}\text { Design platform } \\
\text { of participation }\end{array}$ & Provider & Provider & Provider & Provider \\
\hline
\end{tabular}


Fuster Morell, M. Governance of online creation communities for the building of digital commons: Viewed through the framework of the institutional analysis and development. Madison, M. J., Strandburg, K., \& Frischmann, B. Frischmann, B., Strandburg, K. \& M. Madison (eds.). Governing the Knowledge Commons. Oxford University Press.

\begin{tabular}{|c|c|c|c|c|}
\hline $\begin{array}{l}\text { Participants self- } \\
\text { allocation and } \\
\text { management }\end{array}$ & Yes & Yes & Yes & Yes \\
\hline Formal policies & Provider & Provider & Community & Community \\
\hline License & $\begin{array}{l}\text { Provider } \\
\text { Proprietary } \\
\text { license \& } \\
\text { software }\end{array}$ & $\begin{array}{l}\text { Provider } \\
\text { Free license \& } \\
\text { software }\end{array}$ & $\begin{array}{l}\text { Provider } \\
\text { Free license \& } \\
\text { software }\end{array}$ & $\begin{array}{l}\text { Community } \\
\text { Free license \& } \\
\text { software }\end{array}$ \\
\hline $\begin{array}{l}\text { Decision-making } \\
\text { \& conflict } \\
\text { resolution at } \\
\text { community level }\end{array}$ & No & Yes & Yes & Yes \\
\hline $\begin{array}{l}\text { Infrastructure } \\
\text { provision }\end{array}$ & Closed & Closed & $\begin{array}{l}\text { Open, filtered by } \\
\text { representation }\end{array}$ & Open \\
\hline
\end{tabular}

In sum, the level of control and power over governance of the community of participants, in contrast to the infrastructure provision, are higher in the self-provision assembly model of openesf, followed by the representative foundation of Wikipedia, the mission enterprise of Wikihow, and finally the corporation model of Flickr. However, in all of the cases, participants self-manage their own contribution, and the infrastructure provider depends importantly on the participants in developing the content.

\section{OCCs outcomes}

Following IAD the three exogenous aspects presented in the previous section - resource characteristics, community attributes and governance - contribute to shape the action arena. The action arena is defined by action situations, that is, the design of the situation in which a particular person takes the decision to contribute or not. They can encourage individuals' decisions to participate and collaborate - by solving collective action dilemmas - or on the opposite side discourage them. For Ostrom, (2008: 52) action situations are "composed of 
Fuster Morell, M. Governance of online creation communities for the building of digital commons: Viewed through the framework of the institutional analysis and development. Madison, M. J., Strandburg, K., \& Frischmann, B. Frischmann, B., Strandburg, K. \& M. Madison (eds.). Governing the Knowledge Commons. Oxford University Press.

participants in positions choosing among actions at a particular stage of a decision process in light of their control over a choice node, the information they have, the outcomes that are likely, and the benefits and costs they perceive for these outcomes". Action arenas result in patterns of interaction and, ultimately, those patterns result in particular outcomes. For the sake of space we will not analyze action situations in the context of this chapter.

Additionally, the IAD framework points out that action arenas impact OCCs outcomes. OCCs and cultural commons more generally are building processes. They are not provided by nature as in natural commons, but are constructed and this process is organic to common-pool resources. The ability or inability of OCCs to end in outcomes is a relevant aspect for the IAD. However, it is not clear if Madison, Frischmann and Strandburg take outcomes into consideration in their reframing of the IAD model. However, they do stress that "a cultural commons should be assessed not only in light of its ostensible purposes but also in light of its consequences. This aspect of the case study approach should both identify the consequences and describe relevant criteria for evaluating them." (2008: 705)

In terms of outcomes of OCCs, we would like to differentiate between two sets of outcomes: outcomes in terms of common-pool resources (amount of content, quality of content, usage of content, etc.) and the building process. As common-pool resources in OCCs are built rather than simply "there", we consider it relevant to integrate the capacity of IAD to engage with participation and collaboration in the evaluation of OCCs outcomes, in order to see whether it contributes more benefits than costs and is worth sustaining.

According to the analysis of 50 cases, the four different infrastructure governance models highlighted have different capacities to engage with participation and collaboration in OCCs. First, the analysis suggests that not all the models are able to generate the same size of community. Second, not all the models are able to engage or increase collaboration levels. Third, some models are more suited to complex collaboration than others.

Concerning the two axes ordering infrastructure governance, dependency on 
Fuster Morell, M. Governance of online creation communities for the building of digital commons: Viewed through the framework of the institutional analysis and development. Madison, M. J., Strandburg, K., \& Frischmann, B. Frischmann, B., Strandburg, K. \& M. Madison (eds.). Governing the Knowledge Commons. Oxford University Press.

infrastructure (black box) favors an increase in the size of communities, but impacts negatively on collaboration. Autonomy and freedom from infrastructure (net-enabler conditions) favors more complex collaboration, but negatively affects the size of the community. In other words, larger communities do not require freedom and autonomy conditions if it does not involve complexity in the interaction, but the engagement of complex interaction does.

Concerning the axis of open versus closed to community involvement, the effect is more complex. Openness to involvement in provision favors collaboration where there is some formal organization of participation in the infrastructure provision. Being closed to participation in provision favors an increase in size, but only where provision is based on a forprofit strategy.

In terms of how each of the four models shapes the community, none of the models combine a large community size with collaborativeness. The corporation model generates the biggest communities, based on lower levels of collaboration while the foundation and enterprise models are able to raise mid-sized communities, and are more collaborative. Finally, the assembly model is the weakest in terms of generating (active) OCCs. According to the case studies analysis, these diverse performances could be linked to the diverse ability to generate resources, the ability to manage resources according to organizational strategy, the ability to inspire trust and motivate contributions, and the ability to create conditions favoring collaboration (or not) through the type of license and software and the design of the platform of participation.

In sum, more empowering conditions of the community favor outcomes in terms of collaborativeness, but not size. Of the eight "design principles" that Ostrom (1990) identifies in stable local common pool resource management, two refer to self-governance (collectivechoice arrangements that allow most resource appropriators to participate in the decisionmaking process and self-determination of the community recognized by higher-level authorities). According to the analysis of OCCs, higher self-governance favors collaboration, 
Fuster Morell, M. Governance of online creation communities for the building of digital commons: Viewed through the framework of the institutional analysis and development. Madison, M. J., Strandburg, K., \& Frischmann, B. Frischmann, B., Strandburg, K. \& M. Madison (eds.). Governing the Knowledge Commons. Oxford University Press.

but not a high level of participation in OCCs.

\section{Conclusions}

OCCs are a particular type of cultural or knowledge commons. In this chapter, we provided a characterization of OCCs governance as a complex system in which eight critical aspects define their direction: collective mission or goal of the process; cultural principles/social norms; design of the platform of participation (where regulation is embedded in the code); self-management of contributions; formal policies applied to community interaction; license; decision-making and conflict resolution systems with regard to community interaction; and infrastructure provision.

The sustainable model is also a critical question for OCCs. However, we did not expand on this aspect in the chapter and it might be considered for further research.

The empirical analysis of fifty statistical cases and four case studies reveals the centrality of one of the dimensions in configuring some of the other governance dimensions and in determining the outcomes. However, the self-direction or autonomy of the contributors in allocating their own resources (without command mechanisms) is also a relevant aspect determining the power interplays in OCCs.

\section{Applicability of IAD to OCCs}

In this chapter, we have adapted and applied the IAD framework to OCCs by analyzing the resource characteristics of OCCs, their community attributes and governance, and to then approach how governance of OCCs might explain their ability to raise participation and collaboration.

Clearly this was a very limited application of IAD, as action situations were not 
Fuster Morell, M. Governance of online creation communities for the building of digital commons: Viewed through the framework of the institutional analysis and development. Madison, M. J., Strandburg, K., \& Frischmann, B. Frischmann, B., Strandburg, K. \& M. Madison (eds.). Governing the Knowledge Commons. Oxford University Press.

analyzed, nor the interplay between the different aspects presented. Still we hope it provides an overview of OCCs as an important case of constructed commons and how IAD could be applied.

IAD is a very useful framework to analyze OCCs, as it allows us to approach the interplay between the characteristics of a common-pool resource, the characteristics of a community and the political and institutional arrangements for its governance, and explain how these link to action arenas and ultimately, to outcomes. (Ostrom 2007)

In applying IAD, we build upon previous adaptations. (Madison, Frischmann, and Strandburg, 2010; Schweik and English 2012)

In line with Ostrom's original IAD and Schweik and English's (2012) adaptation of it to the FLOSS case, we consider it useful to retain the differentiation between resource characteristics, community attributes, and rules of law. In contrast, it is stressed less in Madison, Frischmann and Strandburg (2010). Beyond finding it useful to stress the distinction between resource characteristics, community attributes and rules of law as Schweik and English (2012) do in their analysis of FLOSS, we do not fully share Schweik and English's organization of aspects within those three areas. In concrete, Schweik and English present some technological attributes as resource characteristics that are in our opinion part of the regulatory frame of governance, and not a given characteristic of the resource

In line with Lessig (1999), code is law, and rules embedded in the code refer to features that govern interaction among participants and that are inscribed in the technological design of the platform of participation within which the community interacts. Schweik and English seem to consider design principles that are embedded in the platform program and code not to be part of the governance, but as technological attributes in their own right, similar to biophysical characteristics for Ostrom. In our view, rules embedded in the code govern the interaction as much as other rules, and need to be integrated and considered as such in the governance dimension. In a similar vein, Schweik and English consider aspects such as 
Fuster Morell, M. Governance of online creation communities for the building of digital commons: Viewed through the framework of the institutional analysis and development. Madison, M. J., Strandburg, K., \& Frischmann, B. Frischmann, B., Strandburg, K. \& M. Madison (eds.). Governing the Knowledge Commons. Oxford University Press.

leadership or financing as part of community attributes, while we consider these as part of the governance, too.

Coming back to Madison, Frischmann, and Strandburg (2012), the authors seem to suggest de-emphasizing how the clusters of issues to consider are related to the dimensions of outcomes, or the question of the outcome more generally. At least, they note that given the complex dynamics involved, it may be difficult to separate outcomes from the resources and communities that produce them over time. Still, we emphasize that even if difficult, analysis of outcomes is useful. Adopting an IAD based approach may result in expanding the number of variables to consider, which along with the richness of the framework makes it worthwhile. However, without the outcome dimension (or explanatory analysis more generally) we see difficulties for other researchers to adopt the frame, as presenting the clusters suggested by Madison, Frischmann and Strandburg becomes a research project of its own without a similar or specific explanatory line to engage with.

Madison, Frischmann and Strandburgs frame applies to constructing cultural commons as a category. It is the case that constructed cultural or knowledge common-pool resources share some commonalities (more than they do with natural commons); however, it is still a very diverse set. The constructing cultural commons category might be useful for some purposes, but in our view, it is too broad a category to apply IAD equally or uniformly. In this line, the background environment described by Madison, Frischmann and Strandburg does not totally apply or capture the context of OCCs. As Ostrom points out, the evil is in the context and the details (1990). Even if the overall frame of IAD is useful, the clusters of issues related to resource characteristics, community attributes, rules in use, action arenas and outcomes needed to apply IAD to a particular commons need to be much more specified and contextualized for each type of constructed commons.

\section{What defines OCCs as "commons"?}


Fuster Morell, M. Governance of online creation communities for the building of digital commons: Viewed through the framework of the institutional analysis and development. Madison, M. J., Strandburg, K., \& Frischmann, B. Frischmann, B., Strandburg, K. \& M. Madison (eds.). Governing the Knowledge Commons. Oxford University Press.

IAD was developed initially to investigate natural "commons". In this last section, we would like to address the question of the conditions that define the diverse types of "commons" as "commons".

Natural "commons" has received substantial attention. (Ostrom 1990) OCCs are a case, together with many others, of other typology of "commons". In this regard, Hess (2008) provided a rich classification of "new" types of "commons". However, it remains unclear what "commons" have in common. In this line, Benkler (this volume) addresses this issue by raising a very important question: How can we integrate two diverse trajectories of commons "Spanish huertas" (referring to natural commons) and "open roads" - in a general theory of "commons"?

Benkler points out that the resources provided under open access - such as open roads, but that is also the case of OCCs - are also "commons". This is independent of whether they are provided by markets, states, nature or social sources (self-organization). In general, this is a very valuable contribution. Furthermore, it expands the "commons" to other central resources of the system. An open road should be considered a "common" because of its open access character, even if it is provided and governed by the state. However, this question becomes more complex when applied to other types of open access "commons": put concretely, those based on collaborative production and voluntary engagement of the common-pool resource, such as OCCs. What is defined as a "common" in open roads is diverse for Spanish huertas (referring to natural resources), as Benkler pointed out, but also for OCCs in our view. That "commons" should not only consider "instances of self-governance applied to discrete resources sets" (from Benkler this volume) does not imply that governance should not be considered for any type of open access resource.

In our view, for the specific case of OCCs, open access alone is not a sufficient condition. To the open access of the common-pool resource (which Benkler points to) we must add a 
Fuster Morell, M. Governance of online creation communities for the building of digital commons: Viewed through the framework of the institutional analysis and development. Madison, M. J., Strandburg, K., \& Frischmann, B. Frischmann, B., Strandburg, K. \& M. Madison (eds.). Governing the Knowledge Commons. Oxford University Press.

governance design that maintains community control over the collaborative process of building the common-pool resource. In this regard, both open access resources provision and community governance should be considered for characterize OCCs as "commons" to avoid possible confusion. This does not imply that the community governance as a condition for a "commons" in OCCs implies the community governance model of natural "commons", but the community governance in OCCs functioning, as characterized in this chapter.

In the following, we argue why we consider both open access and community governance as conditions for a "commons" in OCCs. In OCCs, the resource is not already available, but needs to be produced and preserved. The production process is based on collaborative and voluntary engagement, and this implies that certain aspects be taken into consideration. On the one hand, the process of production is not based on labor; that is, it is not a contractual relationship of exchanging work per a salary, which tends to be the case when building a road. Rather it is a voluntary and collaborative relationship. This raises the question of whether community could be disempowered from the resource management it produces, and lack control equally in voluntary and collaborative production as in labor conditions. Additionally, this disempowerment in voluntary communities might affect prosocial motivation characteristic of OCCs. A key component to drive community governance in OCCs according to our analysis is the infrastructure governance, because it is important in itself, and because it is a point of control over other dimensions of the governance. Some level of community control over infrastructure is central for community governance as we have argued across this chapter.

Furthermore, the idea of detaching the community from the resource might be questioned. In OCCs the outcome is not only the resources in terms of the archive of knowledge, but the community itself. The resource could not be produced or preserved without the community. In other words, the "production" of the community is a precondition for the possibility to produce the resource. Particularly, in regards to the infrastructure, 
Fuster Morell, M. Governance of online creation communities for the building of digital commons: Viewed through the framework of the institutional analysis and development. Madison, M. J., Strandburg, K., \& Frischmann, B. Frischmann, B., Strandburg, K. \& M. Madison (eds.). Governing the Knowledge Commons. Oxford University Press.

infrastructure governance is not neutral. As we have noted previously in this chapter, infrastructure provision shapes the community and the resource. Again, this raises the question of whether community could be detached from the resource it produces.

If we consider only open access as a condition for OCCs to be a "commons," Flickr and Wikipedia, both with open access resources in different degrees, would be considered a "commons". But could OCCs produced by and/or dependent on for-profit enterprises such as Yahoo! (Flickr) and based on a non-community self-governance model be considered a "commons" just as Wikipedia is based on community self-governance? In order to avoid misinterpretations, we are not pointing to this distinction on the basis of the Flickr corporate for-profit character and the Wikipedia non-profit character, but on the basis of their governance. Wikihow is also for profit, but this is not in conflict with being based upon favoring community governance conditions.

We could argue it from another perspective. As Benkler points, OCCs would be a "commons" when being based in open access. We would agree, if the open access would not only apply to the resource the community produces, but also to the "open access" character of the infrastructure the resource is based upon. This would assure freedom to operate from the infrastructure provider, too.

In sum, common-pool-produced resources should not only be regarded according to how they are provided (open access) and owned (property), but to how they are produced. In other words, the conditions of production and control over the means of production is a highly relevant question.

\section{Bibliographic references}

Angwin, Julia, and Geoffrey A. Fowler, Volunteers Log Off as Wikipedia Ages, WALL St. J., Nov. 27, 2009, http://online.wsj.com/article/SB125893981183759969.html. 
Fuster Morell, M. Governance of online creation communities for the building of digital commons: Viewed through the framework of the institutional analysis and development. Madison, M. J., Strandburg, K., \& Frischmann, B. Frischmann, B., Strandburg, K. \& M. Madison (eds.). Governing the Knowledge Commons. Oxford University Press.

Becker, Markus C., Managing Dispersed Knowledge: Organizational Problems, Managerial Strategies, and Their Effectiveness, 38 J. MGMT. STUD. 1037 (2001).

Benkler, Yochai, The Wealth of Networks: How Social Production Transforms Markets AND FREEDOM (2006).

Benkler, Yochai, Peer Production and Cooperation (forthcoming 2013).

Bimber, Bruce, Andrew J. Flanagin, and Cynthia Stohl, Reconceptualizing Collective Action in the Contemporary Media Environment, 15 COMM. THEORY 365 (2005).

Brown, John Seely, and Duguid, Paul, Organizational Learning and Communities of Practice: Toward a Unified View of Working, Learning, and Innovation, 2 ORG. SCI., no. 1, 1991, at 40.

Burke, Moira and Robert Kraut, Mopping Up: Modeling Wikipedia Promotion Decisions, in PROCEEDINGS OF THE 2008 ACM CONFERENCE ON COMPUTER SuPPORTED COOPERATIVE WorK 27 (2008).

Ciffolilli, Andrea, Phantom Authority, Self-Selective Recruitment and Retention of Members in Virtual Communities: The Case of Wikipedia, 8 FIRST MondAY, no. 12, Dec. 1 2003, http://www.firstmonday.org/issues/issue8_12/ciffolilli/.

Crowston, Kevin, and James Howison, The Social Structure of Free and Open Source Software Development, 10 FIRST MondAY, no. 2, Feb. 7, 2005, http://firstmonday.org/ojs/index.php/fm/article/view/1207/1127.

Forte, Andrea, and Amy Bruckman, Scaling Consensus: Increasing Decentralization in Wikipedia Governance, in PROCEEDINGs of THE 41st ANNUAL HAWAII INTERNATIONAL CONFERENCE ON SYSTEM SCIENCES 157.

FrischmanN, Brett, Infrastructure: The Social VAlue of Shared Resources (2012).Fuster Morell, Mayo (2010). Governance of online creation communities. Provision of platforms for participation for the building of digital commons. (Unpublished dissertation. Defended September 20 2010). Department Social and Political Science. 
Fuster Morell, M. Governance of online creation communities for the building of digital commons: Viewed through the framework of the institutional analysis and development. Madison, M. J., Strandburg, K., \& Frischmann, B. Frischmann, B., Strandburg, K. \& M. Madison (eds.). Governing the Knowledge Commons. Oxford University Press.

European University Institute, Florence. Retrieved from: http://www.onlinecreation.info/outline_design

Glott, R., Schmidt, P., and Ghosh, R. (2009). Wikipedia survey. Working draft. Unu - Merit. Granovetter, Mark, The Strength of Weak Ties: A Network Theory Revisited, in 1 SocIOLOGICAL THEORY 201 (R. Collins ed., 1983).

Greenstein, S., and Devereaux, M. (2009). Wikipedia in the Spotlight. Kellogg Case Number: 5-306-507; HBS Case Number: KEL253. Case Collection at the Kellogg School of Management.

Retrieved

fromhttp://www.kellogg.northwestern.edu/faculty/greenstein/images/htm/Research/C ases/Wikipedia_RVFinal_0709.pdf

Hansen, Morton T., The Search-Transfer Problem: The Role of Weak Ties in Sharing Knowledge Across Organization Subunits, 44 ADMIN. SCI. Q. 82 (1999).

Hess, Charlotte (2008). Mapping the new commons. Conference Governing Shared Resources: Connecting Local Experience to Global Challenges, the Twelfth Biennial Conference of the International Association for the Study of Commons. Cheltenham, England. July 1418, 2008. Retrieved from http://dlc.dlib.indiana.edu/dlc/handle/10535/304

Hess, Charlotte and Elinor Ostrom, Understanding KnOwledge As A Commons: From TheORY TO PRACTICE (2005).

Hill, William C., James D. Hollan, Dave Wroblewski, and Tim McCandless, Edit Wear and Read Wear, in PRoceEdings of THE SIGCHI CONFERENCE ON HUMAN FACTORS IN COMPUTING Systems 3, 1992.Kittur, A., E. Chi, B. Pendleton, B. Suh, and T. Mytkowicz, Power of the Few vs. Wisdom of the Crowd: Wikipedia and the Rise of the Bourgeoisie, in CHI '07: Proceedings of the SIGCHI Conference on Human FaCtors in Computing Systems (2007)..

Konieczny, Piotr, Governance, Organization, and Democracy on the Internet: The Iron Law and 
Fuster Morell, M. Governance of online creation communities for the building of digital commons: Viewed through the framework of the institutional analysis and development. Madison, M. J., Strandburg, K., \& Frischmann, B. Frischmann, B., Strandburg, K. \& M. Madison (eds.). Governing the Knowledge Commons. Oxford University Press.

the Evolution of Wikipedia, 24 Soc. F., no. 1, Mar. 2009, at 162.

Kriplean, Travis, Ivan Beschastnikh, David W. McDonald, and Scott A. Golder, Community, Consensus, Coercion, Control: CS*W or How Policy Mediates Mass Participation, in ProceEdings of THE 2007 InTERNATIONAL ACM CONFERENCE SUPPORTING GROUP Work 167 (2007).

Lanzara, Giovan Francesco, and Michele Morner, The Knowledge Ecology of Open-Source Software Projects, Paper presented at the $19^{\text {th }}$ European Group of Organizational Studies (EGOS) Colloquium, Copenhagen, Denmark (July 3-5, 2003).

Lanzara, Giovan Francesco, and Michele Morner, Making and Sharing Knowledge at Electronic Crossroads: The Evolutionary Ecology of Open Source, Paper presented at the Fifth European Conference on Organizational Knowledge, Learning and Capabilities, Innsbruck, Austria (2004),

http://www2.warwick.ac.uk/fac/soc/wbs/conf/olkc/archive/oklc5/papers/j-

3_lanzara.pdf.

LESSIG, LAWRENCE, CODE AND OTHER LAWS OF CYBERSPACE (1999).

LiH, ANdrew, The Wikipedia ReVolution: How A Bunch of Nobodies Created the WorLd's GREATEST ENCYCLOPEDIA (2009).

Loubser, Max, and Pentzold, Christian (2009). Rule Dynamics and Rule effects in CommonsBased Peer Production. Section: Internet and Politics. Panel: Contemporary Collective Action Dilemmas. 5th ECPR General Conference, Potsdam/Germany, 10-12 September 2009.

Madison, Michael J., Brett M. Frischmann, and Katherine J. Strandburg, Constructing Commons in the Cultural Environment, Cornell Law Review (2010).

Malone, Thomas W., The Future of Work (2004).Matei, S. A., Caius and Dobrescu. (2011). Wikipedia's "Neutral Point of View:"Settling conflict through ambiguity. The Information Society, 27, 1-12. doi:10.1080/01972243.2011.534368 
Fuster Morell, M. Governance of online creation communities for the building of digital commons: Viewed through the framework of the institutional analysis and development. Madison, M. J., Strandburg, K., \& Frischmann, B. Frischmann, B., Strandburg, K. \& M. Madison (eds.). Governing the Knowledge Commons. Oxford University Press.

Negoescu, Radu Andrei, and Daniel Gatica-Perez, Analyzing Flickr Groups, in ProcEEDINGS OFTHE 2008 INTERNATIONAL CONFERENCE ON CONTENT-BASED IMAGE AND VIDEO RETRIEVAL 417 (2008).

Nielsen, Jakob, Community Is Dead; Long Live Mega-Collaboration, JAKOB NiELSEN'S ALERTBOX (Aug. 15, 1997), http://www.useit.com/alertbox/9708b.html.

Nielsen, Jakob, Participation Inequality: Encouraging More Users to Contribute, JAKOB

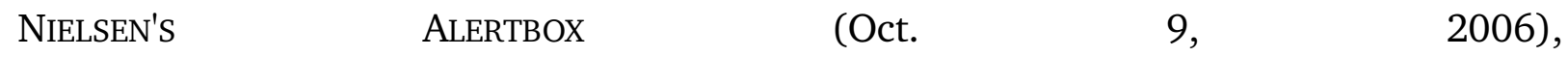
http://www.useit.com/alertbox/participation_inequality.html.

O'Neil, Mathieu, Cyberchiefs: Autonomy And Authority in OnLine Tribes (2009).

O'Mahony, Siobhan, Guarding the Commons: How Community Managed Software Projects Protect Their Work, 32 RES. POL'Y 1179 (2003).

O'Mahony, Siobhan, The Governance of Open Source Initiatives: What Does It Mean To Be Community Managed?, 11 J. MgMt. \& GovernanCE 139 (2007).

O'Mahony, Siobhan, and Fabrizio Ferraro, The Emergence of Governance in an Open Source Community, 50 ACAD. MGMT. J. 1079 (2007).

Orlikowski, Wanda J., The Duality of Technology: Rethinking the Concept of Technology in Organizations, 3 ORG. SCI. 398 (1992).

Ortega, Felipe, Wikipedia: A quantitative analysis. (2009) (unpublished Ph.D. dissertation, Universidad Rey Juan Carlos), available at http://libresoft.es/Members/jfelipe/phdthesis.

Ortega, Felipe, and Jesus M. Gonzalez-Barahona, Quantitative Analysis of the Wikipedia Community of Users, in ProceEdings of THE 2007 INTERNATIONAL SYMPOSIUM ON WiKIS 75 (2007).

Ostrom, Elinor, GOVERning the COMmons: The Evolution of Institutions for Collective ACTION (1990).

Preece, Jenny, Blair Nonnecke, and Dorine Andrews, The Top 5 Reasons for Lurking: Improving 
Fuster Morell, M. Governance of online creation communities for the building of digital commons: Viewed through the framework of the institutional analysis and development. Madison, M. J., Strandburg, K., \& Frischmann, B. Frischmann, B., Strandburg, K. \& M. Madison (eds.). Governing the Knowledge Commons. Oxford University Press.

Community Experiences for Everyone, 20 COMPUTERS HUM. BEHAV., 2004, at 201.

Reagle., Joseph Jr., Open Content Communities, 7 M/C J., no. 3, July 2004, http://journal.media-culture.org.au/0406/06_Reagle.rft.php.

Rose, Carol M., The Comedy of the Commons: Commerce, Custom and Inherently Public Property, in Property and Persuasion: Essays on the History, Theory and Rhetoric of Ownership 105 (1994).

SCHWEIK, CHARLES M. AND ROBERT C. ENGLish, INTERNET SuCCESS (2012).

Shirky, Clay, Here Comes Everybody: The PoWer of Organizing Without Organizations (2008).

Sieberg, Daniel, Flickr on the Fly, 28 ToRсH: U. Victoria AlUMNi Mag., no. 1, Spring 2007, http://web.uvic.ca/torch/torch2007s/feature_5.htm.

Stalder, Felix, and Jesse Hirsh, Open Source Intelligence, 7 FIRST MONDAY, no. 6, June 3, 2002, http://www.firstmonday.org/ojs/index.php/fm/article/view/961.

Stanoevska-Slabeva, Katarina, Toward a Community-Oriented Design of Internet Platforms, 6 INT'L J. ELECTRONIC COM. 71 (2002).

Tkacz, Nathaniel, Power, Visibility, Wikipedia, 40 S. Rev.: Comm., Pol. \& Culture, no. 2, 2007, at 5 .

Viégas, Fernanda B., Martin Wattenberg, and Matthew M. Mckeon, The Hidden Order of Wikipedia, in EOnLINE COMmunities AND SOCIAL COMPUTING 445 (2007).

Weber, Steven, The Success of Open Source (2004). 
A further specification of the methods (codebook, criteria for interview selection, etc.) could be found at http://www.onlinecreation.info/outline_design

ii Sources: Wikipedia http://meta.wikimedia.org/wiki/List_of_Wikipedias\#Grand_Total; Wikihow http://www.wikihow.com/wikiHow:Statistics; and, opennesf entrance website.

iii Weber (2004, 189) also highlights the role of leadership in FLOSS governance. Here, leadership is integrated as part of social norms where informal, and as part of decision-making mechanisms if formal.

iv Source Wikipedia main entrance

"See Frischmann (2012: ch. 8). In addition, Bimber, Flanagin and Stohl (2005) suggest that the free-riding analysis of costs and benefits as applied to information goods is challenged by some of the emerging characteristics of online communities. In the authors' approach the perceived cost of contributing to collective actions via contemporary electronic tools is a relatively weak or even an unimportant factor in explaining individuals' decisions to contribute to information repositories. In their words: "When (contribution) is costly, boundary crossing typically takes on the characteristics of a discrete decision. When participation is easy and not costly, it is less of an issue of a decision" (2005, 378). Second, some contributions do not necessarily involve a decision. For example, in their side effects contributions become "unintended", there is no decision to contribute, the contribution is the result of some other intention, such as using the content.

${ }^{v i}$ Sources: Wikihow statistics page http://www.wikihow.com/Special:Statistics Wikihow daily statistics page for 16 April 2010. 